\title{
El/la trabajador/a social forense en el marco de la Ley Orgánica 5/2000: la entrevista social forense como un encuentro dialógico-empático-emocional ${ }^{1}$
}

\author{
Emiliano A. Curbelo Hernández \\ Doctor y graduado en Trabajo Social, \\ especializado en trabajo social forense \\ emilianocur@gmail.com
}

\begin{abstract}
Artikulu honek adingabearen erantzukizun penala arautzen duen 5/2000 Lege Organikoari buruzko zenbait gai jorratzen ditu, baita ondoren izandako aldaketak ere, Adingabeen Epaitegiari atxikitako talde teknikoko auzitegiko gizarte-langileak adingabeen epaileei eta fiskalei informazioa eta aholkuak emateko dituzten neurri judizialak azaltzearen bitartez. Ondoren, auzitegiko gizartelanaren agertokian, pertsonen arteko harremanetako gizarte-trebetasunei buruzko alderdi batzuk aztertzen dira, hala nola motak, taldeak, ezaugarriak eta haren aplikagarritasun praktikoa, auzitegiko elkarrizketa sozialarekin lotzen dena, elkarren arteko hiru ikuspegitatik: teknika gisa, prozesu gisa eta harreman gisa. Azkenik, ekarpen eta ondorio pertsonal batzuk zehazten dira.
\end{abstract}

\section{GAKO-HITZAK:}

Auzitegiko gizarte-langilea, auzitegiko gizarteelkarrizketa, gizarte-trebetasunak, pertsonen arteko harremanak, eskuartze dialogiko-enpatikoemozionala.
Este artículo aborda algunas cuestiones sobre la Ley Orgánica 5/2000 reguladora de la responsabilidad penal del menor y sucesivas modificaciones, haciendo referencia a las medidas judiciales que el trabajador y la trabajadora social forense del equipo técnico adscrito al Juzgado de Menores, disponen para informar y asesorar a jueces y fiscales de menores. Seguidamente, en el escenario del trabajo social forense, se afrontan algunos aspectos respecto de las habilidades sociales en las relaciones interpersonales como sus tipos, grupos, características y su aplicabilidad práctica, conectando con la entrevista social forense desde tres perspectivas vinculadas entre sí: como técnica, como proceso y como relación. Finalmente, se explicitan algunas aportaciones y conclusiones personales.

\section{Palabras Clave:}

Trabajador/a social forense, entrevista social forense, habilidades sociales, relaciones interpersonales, intervención dialógica-empáticaemocional. 
La fuente fundamental de todos tus errores, sofismas y razonamientos falsos es un total desconocimiento de los derechos naturales de la humanidad. (Alexander Hamilton)

\section{Introducción discursivo-reflexiva}

Transcurridos veinte años desde la entrada en vigor de la Ley Orgánica 5/2000, de 12 de enero, reguladora de la responsabilidad penal de los menores (LORRPM), esta ha constituido una normativa que ha permitido concretizar el principio de oportunidad y adaptar la respuesta jurídica a los ilícitos penales cometidos por los/las menores de edad, considerando y atendiendo realmente a sus circunstancias, en aras de perseguir la reeducación y la ulterior reinserción social desde una visión no punitiva - donde no se habla de penas, sino de medidas - sino sancionadora y reeducativa, a través de la aplicabilidad del repertorio de medidas judiciales establecidas en el artículo 7 de la LORRPM.

Al hilo de lo expuesto, este principio de oportunidad permite al trabajador/a social forense promover el archivo y la conclusión de las actuaciones como medio para evitar judicializar los procedimientos penales, otorgándole la normativa además la facultad para proponer y desarrollar el oportuno proceso de mediación judicial, tratado prolijamente por Curbelo (2008) y Aragón y Curbelo (2004). A ello debemos añadir la transcendental aportación de las ciencias sociales y humanas al procedimiento penal de menores de edad (Curbelo, 2007; Curbelo, 2004a y (Curbelo, 2003b), la cual está orientada hacia un modelo penal juvenil educativo-resocializador en detrimento de otros planteamientos más punitivos y sancionadores, a fin de procurar que, el interés superior del menor, tenga su espacio en el campo jurídico y penal desde una perspectiva integradora (Gortázar, 2002).

En consonancia con lo indicado, Ruiz (2018: 5) señala que esta normativa destaca por "el principio del interés superior del menor; el principio de intervención mínima, el cual no penaliza conductas de escasa importancia; posibilita el sobreseimiento del expediente; y propone la suspensión condicional de la medida o sustitución durante su ejecución, y por último, el principio de no estigmatización”. Y este interés superior del menor que tiene su génesis en las diferentes normativas supranacionales, como señala Sampol (2014: 8) "es un concepto difícil de determinar pero que en esencia implica que la actuación de la justicia penal de menores sólo se produzca cuando sea realmente necesario o dañino un efectivo carácter rehabilitador y educativo".

De este modo, hablamos de principios jurídicos que propician una oportunidad de cambio y transformación del/la menor al amparo de una práctica humanista o de enfoque de derechos, donde no se castiga, sino más bien, sin perder de vista la naturaleza jurídica del ilícito penal cometido, como señala Gortázar (2002) se intenta la búsqueda reeducativa, resocializadora y la positivización del/ la menor.

Y para que ello se pueda concretar, la LORRPM cuenta con un repertorio de medidas judiciales de carácter psicosocioeducativo que no pueden ser represivas sino preventivo-especiales, donde deben primar los derechos del menor 0 , dicho de otro modo, debe ser valorado con criterios técnicos y no formalistas por equipos profesionales especializados en el ámbito de las ciencias no jurídicas, formados por psicólogos/ as, educadores/as y trabajadores/as sociales forenses. Entonces, atendiendo a Curbelo (2002b) podemos diversificar dichas medidas judiciales entre las privativas de libertad o de mayor restricción de derechos y las no privativas de libertad o de menor restricción de derechos, explicitándose seguidamente cada una de ellas, como se observa en la Tabla 1.

Tabla 1. Repertorio de medidas judiciales de la LORRPM

\begin{tabular}{|c|c|}
\hline \multirow{4}{*}{$\begin{array}{l}\text { Medidas privativas de } \\
\text { libertad }\end{array}$} & Internamiento en régimen cerrado. \\
\hline & Internamiento en régimen semiabierto. \\
\hline & Internamiento en régimen abierto. \\
\hline & Internamiento terapéutico. \\
\hline \multirow{10}{*}{$\begin{array}{l}\text { Medidas no privativas } \\
\text { de libertad }\end{array}$} & Tratamiento ambulatorio. \\
\hline & Asistencia a un centro de día. \\
\hline & Permanencia de fin de semana. \\
\hline & Libertad vigilada. \\
\hline & $\begin{array}{l}\text { Convivencia con otra persona, familia o } \\
\text { grupo educativo. }\end{array}$ \\
\hline & Prestación en beneficio de la comunidad. \\
\hline & Realización de tareas socioeducativas. \\
\hline & Amonestación. \\
\hline & $\begin{array}{l}\text { Privación del permiso de conducir } \\
\text { ciclomotores o vehículos a motor, o el } \\
\text { derecho a obtenerlo, o de las licencias } \\
\text { administrativas para caza o para uso de } \\
\text { cualquier tipo de armas. }\end{array}$ \\
\hline & Inhabilitación absoluta. \\
\hline
\end{tabular}

Fuente: Artículo 7 de la LORRPM y Curbelo (2002b).

Estas son las medidas judiciales, cuya aplicabilidad final se determinará por los jueces y fiscales de menores, tras la previa exploración y análisis de las circunstancias del/la menor por parte del/la trabajador/a social forense.

\section{El trabajador/a social forense: interpelación en la práctica profesional a las habilidades sociales en las relaciones interpersonales}

En este espacio, ámbito o contexto, aunque en otros escenarios se pueden concretizar otras más específicas, la disciplina del trabajo social despliega fundamentalmente tres dimensiones: la 
lineal (función pericial forense), la transformadora (función mediadora) y la humanista (función desde un enfoque o perspectiva de derechos) siendo esta última la que debe permear sobre las dos anteriores.

Dicho esto, las habilidades sociales se pueden concretar con mayor exactitud como el conjunto de conductas que emergen en un determinado contexto o escenario en el que se explicitan sentimientos, actitudes, ideas, deseos, comportamientos y opiniones desde una mirada proactiva. Partiendo de un adecuado diagnóstico forense, desde un punto de vista asertivo y de derechos, se propicia la reeducación de los/las menores o, dicho de otra forma, como indican Gil y León (1998), se trata de conductas aprendidas que responden de manera adecuada a las exigencias y demandas de las situaciones sociales.

Efectivamente, debe entenderse que el/la trabajador/a social forense debe aplicarlas no solo desde su saber lógico-racional, sino desde un intercambio dialógico-empático-emocional. Y entonces, por esto último, la mayor parte de la intervención social participativa debe situarse en el ámbito de una comunicación a pares en la entrevista social forense que, junto a otras técnicas propias del trabajo social, permitan afrontar las circunstancias del/la menor, siendo imprescindible como señalan Gil y León (1998) valorar aquellos elementos conductuales, psicofisiológicos, cognitivos y psicosociales.

Asimismo, cabe expresar que la competencia social y las habilidades sociales, en algunos casos, se pueden considerar como conceptos igualitarios o sinónimos y en otros no (Garaigordobil y Peña, 2014). Por ello, el/la trabajador/a social forense debe promover un proceso de retroalimentación en la comunicación para que esta sea circular, transmitiendo información y recibiéndola, dimanando dos enfoques, uno favorable entendido como aquel que refuerza la conducta social, y otro desfavorable, que debilita los talantes interpersonales.

\section{El trabajador/a social forense y los tipos de habilidades sociales emergentes en la práctica profesional}

Cuando nos referimos a los tipos habilidades sociales, nos estamos refiriendo a las diferentes conductas que adoptamos ante una situación o circunstancia determinada o, como indica Ovejero (1990), la conducta socialmente competente depende del contexto social en que se circunscribe. En esta dirección, es importante estar al tanto de los escenarios en la que esta se produce, habida cuenta que en la entrevista social forense podemos encontrarnos ante personas que, en mayor o menor grado, expliciten un repertorio diferente de cada una de ellas. Por eso, surge la urgencia, si cabe, de abundar en los tipos tradicionales de habilidades sociales, como son sustancialmente la conducta asertiva, la pasiva y la agresiva, que se abordan a continuación.

\subsection{La conducta asertiva en el intercambio dialógico}

Se trata de la conducta que más favorece lo dialógico-empático-emocional entre el/la trabajador/a social forense y el/la menor, sus padres o su tutor, habida cuenta que se basa en un intercambio comunicativo afectivo que permite a las partes explicitar sus demandas y necesidades, ser escuchadas e incluso mostrar su desacuerdo ante determinadas cuestiones, pero siempre desde el respeto, el amor y la consideración respecto a los derechos del otro/a.

De este modo, constituye un tipo de conducta que Kelly (2002) entiende como la capacidad de la persona para transmitir sus posturas, opiniones, creencias o sentimientos sin sentirse incómoda, estableciéndose dos tipos distintos de asertividad, la oposición asertiva, donde la persona rechaza la conducta o comentario del otro/a y la aceptación asertiva, en torno a la cual la persona transmite calidez y expresa opiniones positivas hacía los demás, cuando la conducta positiva de estos/as lo justifica, siendo esta última nuestra obligación de cara a favorecer un aprendizaje significativo compartido mediante espacios de reflexión y sociabilidad.

Es más, a nuestro juicio, ser una persona asertiva o socialmente adaptada es sinónimo de presentar altas capacidades de inteligencia emocional, de pensamientos positivos y de resiliencia. De hecho, la perspectiva asertiva permite defenderse óptimamente en las relaciones interpersonales, habida cuenta que normalmente propician una finalidad resolutiva de consecuencias favorables para las partes implicadas, así como una concatenación de procesos que nos llevan a respetar los derechos de los demás, disminuyendo los conflictos, promoviendo un desarrollo social y una certera adaptación personal y social y ambiental.

\subsection{La conducta pasiva en el intercambio dialógico}

En la conducta no asertiva, la persona no defiende sus derechos e intereses personales, no haciéndose respetar, aunque sí respetando a los demás, por lo que, como expresan Eceiza et al. (2008) las causas de las dificultades en las relaciones interpersonales constituyen el resultado de un déficit en habilidades sociales. Ante esto, el/la trabajador/a social forense debe ser el baluarte de la defensa a ultranza de los derechos del/la menor, sus padres y su tutor. En el caso de detectar la existencia de este tipo de conducta, se debe suscitar un contexto de ayuda profesionalizada que fomente procesos conducentes a la sociabilidad, donde prime un horizonte de cambio y transformación. 
A sabiendas de que los/las menores suelen ser incapaces de verbalizar y externalizar sus emociones, sentimientos, opiniones, puntos de vista y preocupaciones de forma adecuada, se debe reforzar su autoestima, entendida esta última, según Caballo y Salazar (2018), como los sentimientos de valía como persona, esa sensación de ser un buen ser humano. Entonces, procede enviarles mensajes positivos, a través de mensajes directos o metamensajes, en suma, prestarles la atención que se merecen y que, en ocasiones, debido a nuestra posición de poder en este contexto judicial, pudiera quedar un poco en el olvido.

Es más, nuestra prioridad debe ser ayudar al/la menor y sus padres o tutores a expresar honestamente sus sentimientos y pensamientos, incluso a reivindicar sus derechos si no están de acuerdo con algunas cuestiones dimanadas del proceso de intervención, cuestión algo difícil cuando el fututo de estos, en parte, depende del pronunciamiento del/la trabajador/a social forense que se trasladará a jueces y fiscales de menores.

\subsection{La conducta agresiva en el intercambio dialógico}

En este punto nos vamos a detener con un poco más de detalle, al ser un aspecto que debe ser adecuadamente canalizado y que suele producirse más habitualmente de lo que se piensa. La conducta agresiva es aquella que impone opiniones, creencias y pensamientos por encima de los/las otros/as, sin importar los efectos que cause dicha conducta, habida cuenta que lo que pretende es obtener sus objetivos sin miramiento alguno, derivándose una serie de elementos que favorecen que esta se intensifique o disminuya. Por ello, Garaigordobil y Peña (2014: 553) refieren que "estos problemas disminuirían significativamente mejorando la autoestima, desarrollando la empatía, aprendiendo a regular los impulsos y las emociones, ejercitando las habilidades sociales y mejorando la expresión de las emociones", aunque, como señala Sampol (2014: 27) los menores de edad "en principio no tienen en su raciocinio capacidad suficiente para establecer la idea de lo que está bien y lo que está mal”.

Esto parece coherente, habida cuenta que en un marco judicial que opera más desde una lógica jurídica que humanista, a pesar que la LORRPM cuenta con un carácter no punitivo y sancionadorreeducativo, el trabajador/a social forense nutrido de utopías de cambio, transformación, desarrollo social y humano, en un mundo distópico, encuentre serias dificultades, retos y barreras para articular un horizonte desde un esquema alternativo de pensamiento, donde el/la menor entienda sus actuaciones disruptivas y sus padres y su tutor comprendan las acciones, conductas y comportamientos cometidos por este.

Ahora bien, como señala la profesora de Trabajo Social Loly Hernández, se debe prestar atención al "dolor" de las personas; solo comprendiendo su origen y sus manifestaciones en la persona, se podrá adoptar una actitud empática entre almas. A modo de ejemplo, si un/a menor está inmerso en un procedimiento penal que, en el peor de los casos, puede llevarlo a una situación de privación de libertad, es absolutamente lógico que su miedo, desconocimiento, temor, ansiedad y el de sus padres o tutor se manifiesten en un repertorio de conductas agresivas, en un entorno desconocido y hermético, donde gestionar este tipo de emociones y estímulos se convierte en una misión casi draconiana.

Antes se hablaba implícitamente de la necesidad de educar en lo comunicativo, en lo asertivo, entendido como la prosecución de conductas socialmente adaptadas, dado que, como indican Del Prette y Pereira (2013: 68), “el aprendizaje de habilidades sociales y el desarrollo de la competencia social constituyen procesos que ocurren naturalmente por medio de las interacciones sociales cotidianas". Llegados a este punto, a continuación, se hablará de las características de las habilidades sociales y su importancia para el/la trabajador/a social en diversas fases del procedimiento penal de menores de edad, con el objeto de constituirse como una figura referente que promueva un aprendizaje educativo que minimice la reincidencia delictiva.

\section{Características de las habilidades sociales en la entrevista social forense}

Tradicionalmente, de forma sucinta, las habilidades sociales se han diferenciado entre las básicas y las complejas. Sin embargo, López (2010) parece ir un poco más allá, describiendo una serie de características que deben ser asumidas, integradas y compartidas por todas las partes, encuadrándose en los grupos que se muestran en la Tabla 2.

La Tabla 2 describe aquellos criterios a los que el/la trabajador/a social forense debe prestar especial atención, nutriéndose de estos de cara a transmitir una adecuada educación y enseñanza $\mathrm{del} /$ la menor y sus padres o tutor para que estos puedan comunicarse desde una simetría dialógicaafectiva, bajo el fundamento del amor, fomentando actitudes que permitan la defensa de sus posturas, posiciones y derechos sin perjudicar al otro/a, es decir, intentar concienciar, mas no convencer, de que "hay que tener en cuenta la necesidad del otro y la interdependencia como factores de convivencia saludable" (Del Prette y Pereira, 2013: 70). Ello garantiza que el/la menor que ha cometido algún delito pueda empatizar y ponerse en el lugar de la víctima o perjudicado y entender su dolor y su sufrimiento.

De esta forma, atendiendo a lo expuesto, el/la trabajador/a social forense debe considerar dichas habilidades sociales en el marco de las relaciones interpersonales, al constituir el camino para un intercambio dilógico-empático-emocional en un 
Tabla 2. Conjunto de habilidades sociales que debería asumir y externalizar el/la trabajador/a social forense

\begin{tabular}{|c|c|c|}
\hline \multicolumn{3}{|c|}{ Características de las habilidades sociales } \\
\hline Grupo I & Primeras habilidades sociales & $\begin{array}{l}\text { Escuchar, iniciar y mantener una conversación, formular una pregunta, } \\
\text { presentarse y presentar a otras personas, dar las gracias, hacer un } \\
\text { cumplido. }\end{array}$ \\
\hline Grupo II & Habilidades sociales avanzadas & $\begin{array}{l}\text { - Pedir ayuda, participar, dar y seguir instrucciones, disculparse, seguir a } \\
\text { los demás. }\end{array}$ \\
\hline Grupo III & Relacionadas con los sentimientos & $\begin{array}{l}\text { Conocer los propios sentimientos y expresarlos y comprender los } \\
\text { de otras personas, expresar afecto, resolver situaciones de miedo, } \\
\text { auto-recompensarse. }\end{array}$ \\
\hline Grupo IV & Habilidades alternativas a la agresión & $\begin{array}{l}\text { - Pedir permiso, compartir, ayudar a los demás, negociar, autocontrol, } \\
\text { defender derechos, evitar conflictos. }\end{array}$ \\
\hline Grupo V & Habilidades para hacer frente al estrés & $\begin{array}{l}\text { - Formular y responder a una queja, demostrar deportividad, resolver la } \\
\text { vergüenza, responder al fracaso y a la persuasión, enfrentarse a mensajes } \\
\text { contradictorios y a la presión del grupo. }\end{array}$ \\
\hline Grupo VI & Habilidades de planificación & $\begin{array}{l}\text { - Tomar iniciativas, establecer objetivos, discernir sobre la causa de un } \\
\text { problema, recoger información, tomar decisiones, resolver los problemas, } \\
\text { concentrase en una tarea. }\end{array}$ \\
\hline
\end{tabular}

Fuente: López (2010: 4-6).

contexto desconocido y lleno de incertidumbres. Y es así como la finalidad debería ir encaminada a construir puentes y tender redes para conformar un escenario sembrado de amor, cordialidad, concordia, empatía, apoyo, respeto, sinceridad, fraternidad, emocionalidad y espiritualidad, de cara a asesorar con los suficientes elementos de juicio la medida judicial y la propuesta socioeducativa más adecuada al ilícito penal cometido por el/la menor, impregnando una mirada "senti-pensante" que garantice mezclar el corazón junto a la razón, todo ello en aras de garantizar los derechos sociales y humanos de estos menores.

Anteriormente se ha mencionado que las personas aprenden de las conductas de los demás y modelan aquellas actitudes que observan. Por ello, cuanto más cordiales, empáticos, amables y cariñosos, afectuosos seamos, cuanto más respuestas satisfactorias y estímulos positivos emitamos y recibamos, más educaremos inconscientemente en valores éticos y morales, sin perder la perspectiva de la exigencia de nuestras funciones como encargados de orientar y asesorar a los correspondientes órganos judiciales y fiscales sobre la medida judicial más acertada, siempre desde la imparcialidad y la neutralidad, y bajo el sometimiento del cumplimiento al imperio de la ley.

Así, hay que combinar la visión tradicional con el enfoque de derechos que Carballeda (2016) señala que permite incorporar la noción de responsabilidad asentada en la necesidad de visibilizar los derechos humanos y sociales. Pero cabe recalcar que dicha perspectiva en absoluto debe justificar el ilícito penal cometido por el/la menor; objetivamente, como trabajadores/as sociales forenses, debemos buscar un equilibrio y equidad entre lo jurídico/legal/penal pero también en lo social/humano.

\section{A propósito de la entrevista social forense: una mirada técnica, procesual y relacional desde una perspectiva reeducativa}

El Diccionario de la Real Academia de la Lengua (2019), establece que intervenir "es la acción y efecto de intervenir" y, según Carballeda (2005), no solo trata de investigar, comprender y explicar, sino que va más allá y busca la transformación de la persona y las circunstancias, siendo la entrevista social en el ámbito que nos ocupa un elemento más de la intervención del trabajo social, conformada por el trabajador/a social, el/la menor, sus padres o tutor y un objetivo concreto, en este caso, la valoración de sus circunstancias para emitir el correspondiente informe pericial forense.

La entrevista, con carácter genérico, puede ser entendida y comprendida como un diálogo entre dos o más personas que acontece en un determinado momento y en un espacio, escenario o contexto para tratar un asunto concreto. Esta ha sido sobradamente tratada y abordada desde áreas del conocimiento relacionadas con las ciencias sociales y humanas, como el trabajo social. De ahí que, para nuestra disciplina no se trate de una simple acción comunicativa puntual sin más, sino más bien consiste en una intervención profesionalizada longitudinalmente que persigue un conjunto de finalidades.

De tal forma, como trabajadores/as sociales forenses, surge la necesidad de conocer en mayor profundidad los elementos epistémicos y metodológicos de la entrevista, desde una perspectiva dialógica-empáticaemocional, al entender que, aunque esta supone una compresión técnica, debemos considerar los procesos emocionales de los diferentes interlocutores/as de 
este proceso transformador y por eso Monetta (2016) comparte que no es casualidad que el discurso de las personas en medio de una crisis no sea ordenado, mostrando un alto contenido emocional, plagado de silencios, de lo que no se puede decir, por lo que acompañar a la persona en el proceso es echar a andar la narrativa.

Ander-Egg (1982) explicita que la entrevista consiste en una conversación entre dos personas, en la cual uno es entrevistador y otro/s entrevistados/ as que dialogan con arreglo a determinadas pautas respecto sobre una cuestión, teniendo un propósito profesional como obtener o facilitar información, influir sobre ciertos aspectos de la conducta o promover un efecto terapéutico. Así que Rossell (1998) señala que la entrevista es una situación interpersonal en la que se establece una relación entre el trabajador/a social y la persona, a lo que deberíamos sumar, "el arte de la conversación, aprendido de modo natural en el curso de la socialización humana" (Pérez et al., 2004: 147).

Dicho ello, es necesario indicar que la entrevista, retomando a Rossell (1998) puede considerarse desde tres ópticas diferentes pero interrelacionadas entre sí, pudiendo ser entendida como relación, como proceso y como técnica. Ahora bien, siguiendo dichos postulados y realizando una analogía con el ámbito que estamos tratando, como relación se traduce en un proceso que se explicita a través de un sentido dialógico-empático-emocional, procesualmente permite ordenar la intervención en una serie de fases, etapas o momentos que aportan coherencia a los objetivos que perseguimos y centrándonos en su aspecto técnico, constituye una técnica más del trabajo social para recabar información sobre las circunstancias del/la menor, sus padres y su tutor, de cara a poder emitir el correspondiente informe forense.

Tras lo enunciado, la entrevista social forense, a nuestro criterio, se puede definir como una sesión de exploración basada en un cuestionario semiestructurado y flexible en el que, mediante un encuentro dialógico-empático-emocional entre almas, mediante un aprendizaje madurativo y afectivo, las diferentes partes, desde una perspectiva de equidad sustentada en el amor fraternal, propician un proceso interpersonal y social basado en el respeto hacia el otro/a, sus relatos, narrativas, historias, experiencias y vivencias, desde un intercambio horizontal basado en un enfoque de derechos que permita un cambio y trasformación social, siendo su finalidad la obtención de información veraz, clara y concisa, con el objeto de poder emitir el correspondiente informe forense que, con suficientes elementos de juicio, permita asesorar y orientar a jueces y fiscales de menores sobre la medida judicial y la propuesta socioeducativa más acertada a cada caso².

${ }^{2}$ Se da por sentado que también cabe pronunciarse sobre la idoneidad de iniciar el proceso de mediación judicial o incluso proponer el archivo y la conclusión de las actuaciones.
A la vez, supone un intercambio de ideas, sentimientos, pensamientos, percepciones que reconozcan al/la trabajador/a social forense como agente de orientación y acompañamiento, aportar pautas educativas a las partes, para crear un espacio de aprendizaje conjunto que maximice un comportamiento asertivo que minimice o evite nuevas reincidencias delictivas.

Asimismo, cabe citar que, seguidamente, se integrará la visión técnica y relacional de la entrevista, mencionadas con anterioridad, dentro de las diferentes fases procesuales que, a nuestro criterio, conforman la entrevista social forense: la fase preliminar o de preparación, la fase de recepción, la fase de desarrollo o de exploración y la fase de final o de cierre. A continuación, se conocerá cada una de ellas:

\subsection{Fase preliminar o de preparación}

Consiste en estudiar el caso previamente, revisar la documentación existente, el expediente de reforma $\mathrm{del} /$ la menor y sus antecedentes policiales y judiciales si los hubiera, analizar la información dimanada de informes de organismos públicos y entidades, organizar el espacio y ajustar los tiempos para celebrar el encuentro, convirtiéndose en un encuentro que, como señalan Martorell y González (1997), es una reunión fijada y determinada de antemano en la cual hay claramente dos o más partes.

\subsection{Fase de recepción}

Consiste en dar la bienvenida al/la menor y sus padres o tutor o en el caso de menores insertos en el sistema de protección de menores, tanto nacionales como extranjeros, con el técnico correspondiente de la entidad de protección a la infancia. En este momento, a los implicados/as se les debe explicar brevemente en qué va a consistir el proceso a realizar y las normas básicas que se deben cumplir.

\subsection{Fase de desarrollo o exploración}

Consiste en realizar la recogida de información imbricándose en esta fase la perspectiva técnica y la relacional que se abordará a continuación:

\subsubsection{La entrevista social forense como técnica en el proceso de exploración}

En este caso es necesario señalar que en la fase de desarrollo, técnicamente, primeramente se entrevistará al/la menor de forma individual para valorar su percepción de lo ocurrido y analizar sus circunstancias en función de sus verbalizaciones; posteriormente se procederá a hablar con sus padres o tutor para informarles de los hechos de los que es acusado su hijo/a en caso de desconocerlos, informen de sus circunstancias y de las de su hijo/a 
y para además, conocer si tras los acontecimientos sucedidos han adoptado algún reproche o acción socioeducativa sobre este; $y$, finalmente, se entrevistará a todas las partes conjuntamente para contrastar toda la información que haya ido fluyendo durante el proceso de entrevista y constatar los diferentes puntos de vista.

Lo dicho implica para el/la trabajador/a social forense el reconocimiento de una capacidad teórico-práctica y el uso de estrategias que permitan identificar las circunstancias del/la menor a través de instrumentos que detecten las diferentes problemáticas, no solamente desde ese "ojo de buen cubero", aunque es cierto que no se cuenta con muchos instrumentos debidamente homologados para realizar un adecuado diagnóstico forense, y por lo tanto, bajo estas deficiencias, se debe hacer uso de herramientas propias del trabajo social con carácter general como son la propia entrevista, el ecomapa, el genograma, las historias de vida, la visita domiciliaria, etc.

Seguidamente, con carácter general, se presentan algunos de los indicadores que deben ser objeto de exploración por parte del/la trabajador/a social forense en la entrevista social forense y que servirán de guia para identificar las circunstancias del/la menor y para la elaboración y emisión del ulterior informe forense (2004b): datos personales, familiares, sanitarios, de la vivienda, educativos, socioeconómicos, sociales, laborales, penales y policiales, ambientales, del entorno y de servicios sociales o del sistema de protección a la infancia.

Desde nuestra disciplina, en la entrevista social forense como técnica, el/la trabajador/a social forense utiliza una serie de conocimientos teóricoprácticos para recopilar información acerca de las circunstancias del/la menor y sus padres o tutor, constituyéndose como una pieza clave en este entramado dialógico, comunicativo y social. Efectivamente, se infiere que esta es una conversación formal que cuenta con una estructura propia para obtener la máxima información y lograr el cumplimiento de los objetivos preestablecidos (Fernández y Bracho, 2003).

Así, el/la trabajador/a social forense debe comparar la información obtenida en la entrevista social forense con el resto de documentación a su disposición dimanada de la solicitud a otros organismos o entidades. Si el/la menor está tutelado, además, el educador/a del centro de acogida, el representante de la entidad pública o bien la familia de acogida pueden aportar mayor luz respecto de sus circunstancias, para poder decidir la medida judicial más acorde a sus necesidades, buscando el equilibrio o la equidad entre una postura permisiva y una extrema, o incluso proponer el archivo y conclusión de las actuaciones cuando se detecten situaciones sociales que no sean susceptibles de abordarse desde el ámbito de la reforma, pero sí requieran su derivación a los servicios sociales o el sistema de protección a la infancia.
5.3.2. La entrevista social forense desde un punto de vista relacional en el proceso de exploración

En este encuentro entre almas se establece una reciprocidad entre el/la trabajador/a social forense y el/la menor, padres o tutor. Por ello, la entrevista no es solo una técnica mecánica en la que el entrevistador aplica los métodos científicos, sino que existe una relación humana y afectiva 0 dialógica-empático-emocional.

De esta forma, Rossell y Rodríguez (2017) exponen que la entrevista es una de las herramientas básicas en el campo de las ciencias sociales, si bien a menudo se olvidan sus aspectos psicodinámicos, que hacen referencia a los intercambios afectivos entre el entrevistado y el entrevistador, hablándose escasamente de las vivencias que emergen en este tipo de interrelación personal. En nuestra opinión esto supone una negligencia que puede dificultar el logro de objetivos, impidiendo delimitar con claridad las situaciones problemáticas y su ulterior proceso resolutivo; de ahí que Monetta (2016: 63) exprese que "todo acto dialógico como la entrevista tiene potencial de transformación [...] que permiten reconstruir historias de vida, acceder al impacto en la biografía del sujeto de los padecimientos sociales, inscribir este padecimiento en la trama social más amplia". En este aspecto, en torno al/la trabajador/a social forense, este explicita numerosos roles en su actuación profesionalizada que, necesariamente, deben exhibirse en la entrevista social forense desde su perspectiva relacional, siendo los más importantes en este escenario los que muestra la Tabla 3.

Tabla 3. Roles del trabajador/a social forense en la entrevista social forense

\begin{tabular}{|c|c|}
\hline $\begin{array}{l}\text { Empáticos y } \\
\text { emocionales }\end{array}$ & $\begin{array}{l}\text { - Prestar especial énfasis en el proceso } \\
\text { relacional al otro/a interpelando a la } \\
\text { importancia de una base humana y empática- } \\
\text { emocional. Promover el amor fraterno hacia } \\
\text { sí mismo y hacia los/las demás reconociendo } \\
\text { el poder de los valores en la vida como } \\
\text { la sinceridad, igualdad, justicia social, } \\
\text { libertad, responsabilidad, empatía, ayuda, } \\
\text { comprensión, compasión, etc. Fomentar una } \\
\text { perspectiva fundada en derechos. }\end{array}$ \\
\hline $\begin{array}{l}\text { Dialógicos y } \\
\text { fomentadores }\end{array}$ & $\begin{array}{l}\text { Potenciar el diálogo, la comunicación y } \\
\text { los procesos interpersonales, entre el/la } \\
\text { menor, sus padres o tutor promoviendo sus } \\
\text { potencialidades y fortalezas y no solamente } \\
\text { teniendo en cuenta los aspectos negativos y } \\
\text { las vulnerabilidades. }\end{array}$ \\
\hline $\begin{array}{l}\text { Educativos y } \\
\text { reeducativos }\end{array}$ & $\begin{array}{l}\text { - Defensa de los derechos sociales y humanos. } \\
\text { - Fomentar la participación y aportación activa } \\
\text { del/la menor a la sociedad. } \\
\text { - Concienciación de sus obligaciones y deberes } \\
\text { individuales y sociales para el fomento de su } \\
\text { responsabilidad personal. } \\
\text { - Enseñar a adoptar conductas asertivas y } \\
\text { constructivas de mejora individual, familiar } \\
\text { y social. } \\
\text { - Reflexionar sobre las multiexperiencias vitales } \\
\text { del/la menor y su entorno. } \\
\text { - Concienciar sobre el delito cometido hacia la } \\
\text { víctima o perjudicado o contra la comunidad } \\
\text { para qué empatice con el dolor ajeno. }\end{array}$ \\
\hline
\end{tabular}

Fuente: Elaboración propia. 
Al hilo de lo señalado, el/la trabajador/a social forense debe hacer visibles todos y cada uno de estos roles para que, en cierto modo, permitan un crecimiento personal, social y emocional, evitando nuevos comportamientos delictivos o minimizar el impacto delictual. Así, se debe ayudar y concienciar al/la menor, sus padres y su tutor sobre la capacidad para diagnosticar o concretar las causas y el origen de los conflictos, sin pronunciamientos de culpabilidad, ni prejuicios, ni estigmatizaciones y dicha valentía debe realizarse desde el amor y conjuntamente entre todos/as. De la misma forma, se debe orientar en la búsqueda del mayor número posible de alternativas y soluciones, haciéndoles conocedores que cualquier situación de malestar social suele tener más de una salida.

En esta misma dirección, el/la trabajador/a social forense no solamente debe exponer las soluciones que pudieran subyacer ante una determinada situación, sino permitir que el/la menor, los padres o el tutor aporten las suyas propias y de forma conjunta, cumpliendo con el principio de libertad y autodeterminación, propongan aquella/as que consideren más adecuadas desde una mirada donde "cuatro ojos ven más que dos".

A la misma vez, se debe enseñar al/la menor a anticiparse a los hechos, sucesos y acontecimientos, previendo las consecuencias; así, el/la trabajador/a social forense debe interpelar a una cosmovisión de futuro trasladándoles las posibles consecuencias de sus decisiones y actos, pero siempre respetando su libre albedrío a la hora de tomar el camino que consideren más oportuno, siempre que no entre en contradicción con el interés superior del/la menor.

Por otro lado, el/la trabajador/a social forense conjuntamente debe seleccionar el mejor camino o proceso para conseguirlo, a modo de equipo de trabajo y desde una visión de trabajo en equipo, lo que para Carballeda (2001) se presenta como una posibilidad de construir algo diferente en la medida en que pueda incorporar el concepto de diálogo por encima de la imposición.

Por último, es vital ponerse en el lugar del otro/a, transitando el egocentrismo, comprendiendo la libertad de elección del ser humano en todas sus dimensiones. Ello supone adoptar en la intervención una mirada "senti-pensante", es decir, sentir desde el corazón apelando al amor y la fraternidad, sin perder de vista el pensamiento y la perspectiva lógica-racional que emana de nuestros conocimientos disciplinares, respetando los derechos de la persona, pero haciéndole ver también sus deberes y los errores cometidos.

\subsection{Fase de final o de cierre}

Se trata del proceso final de la entrevista, en la que el/la trabajador/a social forense informará sobre sus apreciaciones sobre el proceso y respecto lo que acontecerá a continuación, es decir, en la siguiente fase procesal del procedimiento. Como profesionales deberíamos conjuntamente con el/la menor, sus padres o el tutor, sacar las conclusiones finales del camino dilógico, estando en nuestras manos, como técnicos forenses de lo social, el pronunciamiento final de lo que debe recogerse en el informe forense que se enviará a los jueces y fiscales de menores, siendo necesario consultar a todas las partes sobre las acciones que consideran deberían realizarse respecto al caso.

Hay que tener cierta precaución, habida cuenta que el/la menor, en algunos momentos, manifestará sus deseos de que se archive el expediente prometiendo que no volverá a reproducir ese tipo de conductas disruptivas y, en parte, puede ser así, si bien esto debe ser analizado con suma cautela, aunque, por experiencia como trabajador social forense, los padres suelen ser más objetivos y coherentes a la hora de pronunciarse al respecto, incluso recomendando medidas más restrictivas que sirvan de escarmiento a el/la menor que ha cometido un ilícito penal.

En cualquiera de los casos, la información facilitada deberá respetar y responder a los principios de confidencialidad y secreto profesional, no preguntando, $\mathrm{ni}$ indagando en cuestiones superfluas que nada tengan que ver directamente con nuestras competencias, ni con el objetivo de nuestra función.

No debemos olvidar que desde el momento de la entrevista social forense hasta la fecha de señalamiento del juicio oral puede transcurrir mucho tiempo. Por lo tanto, bien sea por la necesidad de actualizar la información por haber transcurrido más de tres meses desde la emisión del informe forense, bien por que el/la menor haya cometido un nuevo episodio delictivo o porque se solicite una comparecencia para la modificación o sustitución de la medida judicial impuesta, en cualquiera de los supuestos, se debe plantear un nuevo encuentro para volver a valorar las circunstancias, con el objeto de disponer de nuevos elementos de juicio que nos permitan mantener o modificar el contenido de nuestro informe forense.

\section{Conclusiones para la discusión y debate: abundando en un proceso reflexivo}

Después de todo lo señalado, poco queda por añadir, si bien se pueden presentar las siguientes consideraciones generales:

- La LORRPM es una de las más avanzadas del mundo en materia de reforma de menores, a través de su concepción sancionadora-reeducativa y por las características de las medidas judiciales de carácter psicosocioeducativo recogidas en el artículo 7 y desde nuestra mirada como expertos sociales forenses doctos en las ciencias sociales y humanas, todo ello constituye una oportunidad 
socio/jurídico/legal para promover verdaderos espacios reeducativos y resocializadores de los/las menores que han cometido algún tipo de ilícito penal. De este modo, se garantiza el cumplimiento de un enfoque humanista y de derechos dimanados de las normas nacionales y supranacionales de protección a la infancia, como indica Gortázar (2002) la Constitución Española, la Convención de los Derechos del Niño, las Reglas de Beijing, el Código Penal español, etc.

- La práctica profesional del/la trabajador/a social forense en este escenario necesita de un encuadre que, cumpliendo las funciones y competencias propias que nos atribuye la LORRPM, permita entender y comprender que cuanta más humanidad y amor imprimamos a nuestra práctica profesional, mayores beneficios compartidos, debiendo por ello transitar del paradigma del "amor por el trabajo social" al "trabajo social con y desde el amor" o parafraseando a Ander-Egg (2011: 148) “debiendo considerar que debemos confiar en las personas, comprendiendo que todos somos una mezcla de grandezas y miserias, de luz y de sombras".

- Las habilidades sociales en las relaciones interpersonales que se hacen presentes en la entrevista social forense constituyen la mejor arma del/la trabajador/a social forense para hacer frente a la multiplicidad de situaciones problemáticas. Promover y fomentar conductas asertivas supone una mayor garantía resolutiva de éxito en los procesos de exploración de las circunstancias del/la menor. Y para que ello se pueda cumplir, debemos comprender a los/las menores, sus padres y tutor bajo el paraguas de sujetos protagonistas de sus propios procesos de cambio y transformación, apelando a cuestiones garantistas que cumplan con los derechos sociales y humanos legalmente reconocidos, pero sin que ello suponga necesariamente entrar en conflicto con nuestro quehacer profesional, habida cuenta que, como hemos indicado, estamos sometidos a principios como la imparcialidad, la neutralidad y el sometimiento al cumplimiento del imperio de la ley en nuestras valoraciones como trabajadores/as sociales forenses.
- La entrevista social forense no solamente nos va a permitir diagnosticar las circunstancias del/la menor, su familia y su entorno, sino que además nos servirá como una oportunidad para promover un espacio educativo donde a todos/ as se les haga entender las consecuencias de sus actos, las alternativas para afrontar sus diversas problemáticas, para poder concretar su origen, permitiendo que afloren la mayor parte de soluciones posibles y sean estas las que, cumpliendo con el principio de libertad y autodeterminación, propongan aquella/as que consideren más adecuadas, haciéndole sobre todo entender al/la menor las consecuencias de los hechos ilícitos cometidos y el sufrimiento y dolor causado a la víctima o perjudicado por lo ocurrido o de los daños producidos a la comunidad, todo ello desde la concienciación y nunca desde la imposición.

- Es conveniente tener en cuenta que, antes que trabajadores/as sociales forenses, somos seres humanos y, por tanto, cargamos una mochila que nos hace percibir la realidad y el entorno que nos rodea conforme a nuestro modo de entender y comprender el mundo, estando influenciados por criterios políticos, ideológicos, filosóficos, políticos, personales, sociales, y profesionales; por esta razón, nace la imperiosa necesidad de dejar atrás todo tipo de prejuicios y juicios de valor innecesarios, para que nada de lo expuesto influya de modo alguno en nuestra toma de decisiones. De este modo, nace la urgencia de convertirnos en profesionales "senti-pensantes" unir nuestro corazón y nuestro conocimiento disciplinar, y ello no debe servir para justificar los actos delictivos cometidos por los/las menores de edad por el mero hecho de serlos, sino que significa reprochar su conducta de forma asertiva, debiendo en cualquier caso evitar su estigmatización por haberse visto insertos en la comisión de un acto delictivo, centrando el foco en una atención preventiva que preste especial énfasis a las circunstancias que pudieran haber servido de revulsivo para que dichos actos punibles fueran cometidos, intentando hacerle comprender que el camino delictual no constituye la mejor opción de vida. 
ANDER-EGG, E. (1982): Técnicas de investigación social, Alicante, Humanitas.

- (2011): “Humanismo y Trabajo Social”, Interacción y Perspectiva Revista de Trabajo Social, Vol. 1, no 2, pp. 142-151.

ARAGÓN y CURBELO, E. (2004): “Aspectos psicosociales de la función mediadora en la justicia penal juvenil española desde la Ley Orgánica 5/2000", Nómadas, nํ9, pp. 1-6.

CABALLO, V.; SALAZAR, I. y EQUIPO DE INVESTIGACIÓN CISCO-ESPAÑA (2018): “La autoestima y su relación con la ansiedad social y las habilidades sociales", Behavioral Psychology/ Psicología Conductual, Vol. 26, no- 1, pp. 23-53.

CARBALLEDA, A. (2001): "La interdisciplina como un diálogo. Una visión desde el campo de la salud", Revista Margen, $\mathrm{n}-23$.

- (2008): “La intervención en lo social y las problemáticas sociales complejas: los escenarios actuales del Trabajo Social", Revista Margen, nํ48.

- (2016): "El enfoque de derechos, los derechos sociales y la intervención del Trabajo Social”, Revista Margen, $\mathrm{n}$ 응.

CURBELO, E. (2002a): "El informe técnico desde la óptica del trabajo social en la ley $5 / 2000$ ", Servicios Sociales y Política Social, n- 57, pp. 129-134.

- (2002b): "Las medidas judiciales en la Ley Orgánica 5/2000; Instrumentos de reinserción social”, Revista Trasfondo Social, no 2, pp. 1-12.

- (2003a): "Funciones específicas de los trabajadores sociales en el marco de la Ley penal del menor 5/2000", Servicios Sociales y Política Social, no 61, pp. 123-134.

- (2003b): “Aproximación al trabajo social forense en el ámbito de la Ley penal del menor 5/2000",
Documentos de trabajo social: Revista de trabajo social y acción social, n-29, pp. 115-131.

- (2004a): “Reflexiones socioeducativas acerca de la Ley Orgánica 5/2000, de 12 de enero, reguladora de la responsabilidad penal del menor", Entorno Social, nํ-57, pp. 1-9.

- (2004b): “Circunstancias sociofamiliares y del entorno objeto de estudio para el trabajo social en la Ley Orgánica 5/2000 reguladora de la responsabilidad penal del menor", Trabajo Social Hoy, nํ- 42, pp. 33-50.

- (2007): “Indagando en la práctica profesional de los trabajadores y trabajadoras sociales forenses del equipo técnico de la fiscalía y el juzgado de menores", Acciones e Investigaciones Sociales, no 24, pp. 5-42.

- (2008): "Trabajo social y mediación judicial: el trabajador social forense como mediador en el contexto de la mediación penal de menores de edad", Humanismo y Trabajo Social, Vol. 7, pp. 135-154.

DEL PRETTE, A. y PEREIRA, Z. (2013): "Programas eficaces de entrenamiento en habilidades sociales basados en métodos vivenciales", Apuntes de Psicología Colegio Oficial de Psicología de Andalucía Occidental, Vol. 31, nํㅜ 3, pp. 67-76.

ECEIZA, M.; ARRIETA, A y GOÑI, A. (2008): "Habilidades sociales y contextos de la conducta social", Revista de Psicodidáctica, Vol. 13, nํㅜ 1, pp. 11-26.

FERNÁNDEZ, T. y BRACHO, C. (2003): Introducción al Trabajo Social, Madrid, Alianza Editorial.

GARAIGORDOBIL, M. y PEÑA, A. (2014): “Intervención en las habilidades sociales: efectos en la inteligencia emocional y la conducta social", Behavioral Psychology/Psicología Conductual, Vol. 22, no 3, pp. 551-567. 
GIL, F. y LEÓN, J.M. (1998): Habilidades Sociales. Teoría, investigación e intervención, Madrid, Síntesis.

GORTÁZAR, E. (2002): "Los equipos técnicos en justicia de menores”, Política Social y Servicios Sociales, nํ⒌ 57, pp. 119-128.

LÓPEZ, E. (2010): “El desarrollo de las habilidades sociales", Revista digital de innovación y experiencias educativas, $\mathrm{n}$ - 31, pp. 1-9.

MARTORELL, M. y GONZÁLEZ, R. (1997): Entrevista y consejo psicológico, Madrid, Síntesis.

MONETTA, L. (2016): "Reflexiones en torno a la entrevista en Trabajo Social como instancia de intervención", Revista del Departamento de Ciencias Sociales, Vol. 4, nํㅜ 1, pp. 91-101.

OVEJERO, A. (1990): “Las habilidades sociales y su entrenamiento; un enfoque necesariamente psicosocial”, Psicothema, nํ 2, pp. 93-112.
PÉREZ, E.; GOMÁ, H.; VILLALTA, M. y TORRES, M. (2004): Contexto y metodología de la intervención social, Barcelona, Altamar.

KELLY, J.A. (2002): Entrenamiento de las habilidades sociales, Bilbao, Desclée de Brouwer.

ROSELL, T. y RODRÍGUEZ, P. (2017): La entrevista en Trabajo Social, Barcelona, Herder.

ROSELL, T. (1998): La entrevista en el Trabajo Social, Barcelona, Euge.

RUIZ, I. (2018): La mediación en el ámbito penal de menores, Trabajo de Fin de Máster, Valladolid, Universidad de Valladolid.

SAMPOL, S. (2014): Medidas aplicables a menores de edad según la Ley Orgánica 5/200o de 12 de enero, reguladora de la responsabilidad penal de los menores, 4 GDRET, Islas Baleares, Universitat de les Illes Balears.

\section{Normativa y legislación}

Ley Orgánica 5/2000, de 12 de enero, reguladora de la responsabilidad penal del menor. 